\title{
Recurrent Cervical Carcinoma
}

National Cancer Institute

\section{Source}

National Cancer Institute. Recurrent Cervical Carcinoma. NCI Thesaurus. Code C7804.

The reemergence of cervical carcinoma after a period of remission. 